\title{
Article
}

\section{Evaluation of cross-contamination of nylon bags with heavy loaded gasoline fire debris and with automotive paint thinner}

Belchior, Filipa and Andrews, Stephen Paul

Available at http://clok.uclan.ac.uk/15536/

Belchior, Filipa and Andrews, Stephen Paul ORCID: 0000-0003-0878-1182 (2016) Evaluation of cross-contamination of nylon bags with heavy loaded gasoline fire debris and with automotive paint thinner. Journal of Forensic Sciences, 61 (6). pp. 1622-1631. ISSN 0022-1198

It is advisable to refer to the publisher's version if you intend to cite from the work. http://dx.doi.org/10.1111/1556-4029.13185

For more information about UCLan's research in this area go to http://www.uclan.ac.uk/researchgroups/ and search for <name of research Group>.

For information about Research generally at UCLan please go to http://www.uclan.ac.uk/research/

All outputs in CLoK are protected by Intellectual Property Rights law, including Copyright law. Copyright, IPR and Moral Rights for the works on this site are retained by the individual authors and/or other copyright owners. Terms and conditions for use of this material are defined in the policies page. 


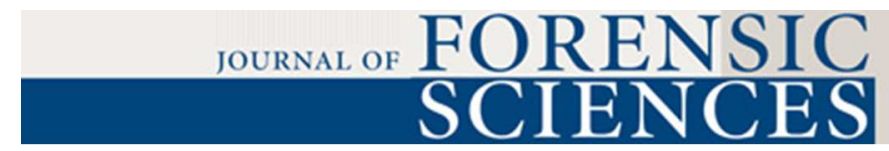

\section{Evaluation of cross-contamination of nylon bags with heavy loaded gasoline fire debris and with automotive paint thinner}

\begin{tabular}{|r|l|}
\hline Journal: & Journal of Forensic Sciences \\
\hline Manuscript ID & JOFS-15-409.R1 \\
\hline Danuscript Type: & Technical Note \\
\hline Complete List of Authors: & $\begin{array}{l}\text { Belchior, Filipa; University of Central Lancashire, School of Forensic and } \\
\text { Applied Sciences } \\
\text { Andrews, Stephen; University of Central Lancashire, School of Forensic and } \\
\text { Applied Sciences }\end{array}$ \\
\hline Keywords: & $\begin{array}{l}\text { Forensic Science, fire debris, nylon bag, evidence container, packaging, } \\
\text { contamination }\end{array}$ \\
\hline & \\
\hline
\end{tabular}

SCHOLARONE ${ }^{m}$

Manuscripts 
Evaluation of cross-contamination of nylon bags with heavy loaded gasoline fire debris and with automotive paint thinner*

Filipa Belchior ${ }^{1}$, M.Sc.; Stephen P. Andrews, M.Sc.

School of Forensic and Applied Sciences

University of Central Lancashire

Preston PR1 2HE

United Kingdom

${ }^{1}$ Present address: Judiciary Police, Scientific Police Laboratory, Polícia Judiciária, Rua Gomes Freire, 1169-007 Lisboa, Portugal.

* Presented at the CEPOL Annual European Police Research and Science Conference, October 5-8, 2015, in Lisbon, Portugal. 


\begin{abstract}
Nylon bags are used for packaging fire debris in several countries, particularly in Europe. The possibility of cross-contamination during transport from the fire scene to the laboratory, in normal casework conditions in the UK, was studied for two brands of nylon bags, using simulated heavy loaded fire debris. Three experiments were carried out with each brand, using as sample a piece of cotton fabric soaked with gasoline. One experiment was carried out using automotive paint thinner (oxygenated solvent). Each sample was sealed in a nylon bag and stored in contact with eight empty bags. The empty bags were analysed at regular intervals for a period of time up to eight weeks, using SPME and GC/MS. Cross-contamination was found for components of gasoline (toluene and $\mathrm{C}_{2}{ }^{-}$ alkylbenzenes) in the two brands of nylon bags used, after 4 days and 2 weeks. Crosscontamination using automotive topcoat thinner was detected after 2 days.
\end{abstract}

Key words: Forensic Science, fire debris, nylon bag, evidence container, packaging, contamination 
Nylon bags are used in several countries and are the most used container in the UK. It has been known for many years that they are not completely vapour proof and do not retain alcohols and other polar compounds $(1,2)$. Contamination and cross-contamination of nylon bags (the presence of volatiles from one sample being identified in the adjacent sample) must be prevented, and evidence should be packed in a container that prevents loss or addition to the material. Minor contamination of fire debris evidence may produce misleading results, providing false information about the possible origin and cause of a fire, or falsely linking a suspect to a scene. The possibility of cross-contamination between nylon bags may have implications in the way samples are transported between the fire scene and the laboratory, and how they are stored in the laboratory.

Several studies have been carried out in the last decades to evaluate leakage and crosscontamination of nylon bags. The results regarding leakage agreed that nylon bags do leak after some time, however the conclusions for cross-contamination were different. These studies used different brands of bags and varied in the classes of ignitable liquids used, the amount, sealing procedure, the time leaking was detected and the experimental conditions (2-8).

The purpose of this study was to evaluate if there was cross-contamination between a nylon bag containing fire debris heavily loaded with gasoline and nylon bags in close contact with it, in conditions similar to the ones used in the UK by fire investigators and crime scene investigators (CSIs) in the field, which may result in false positive identification. Two brands of nylon bags were used for these experiments. A second experiment was done using automotive topcoat thinner, an oxygenated solvent, only with one of the brands of nylon bags because it is one of the most commonly used by fire investigators in the UK, and in order to compare its performance with different products. For the two brands used in this study, the manufacturer BVDA states in their website that 
nonpolar compounds diffuse through nylon bags at low rates (9), and the website of CSI Equipment publishes that nylon bags have a low permeability to hydrocarbons and other volatile materials (10).

Gasoline was chosen for studying the possibility of cross-contamination between nylon bags because it is the ignitable liquid most frequently found in fire debris in the UK (11), the United States (12) as well as one of the most common in Japan (13). The aim of using heavy loaded gasoline samples in this study was to simulate real cases where large amounts of gasoline have been used, for example a fire where gasoline is poured around a scene, forming a trail on the carpet, or a Molotov cocktail wick. The oxygenated solvent used was automotive topcoat thinner, for studying a different class of ignitable liquids that is readily available.

Although fire debris analysts are usually aware of the possibility of cross-contamination of nylon bags, and they have technical knowledge of the strong and weak points of fire debris containers, both of the authors personal experiences have shown that some fire investigators and crime scene examiners often are not.

Furthermore, whilst best practice is to analyse samples within 24-48 hours after collection at a fire scene, in actual case work this is not always the case. In the UK, since the privatisation of forensic science provision, it is common practice only to analyse debris samples after a suspect has been identified and/or arrested, unless the case is particularly serious, for example in a murder enquiry. Even then, the analysis is often delayed by the requirement to hold forensic strategy meetings so that the most promising samples are sent for analysis on a cost-benefit basis. It is not unusual for samples to be stored in a CSI storeroom for several weeks prior to submission to the analytical laboratory. 


\section{Materials and methods}

Nylon bags and ignitable liquids

Two brands of nylon-11 bags were used, from CSI Equipment, UK, 460mm x 600mm and $0.04 \mathrm{~mm}$ thick (experiments 1, 2, 3 and 7), and BVDA International, Holland, 250mm x 500mm and $0.04 \mathrm{~mm}$ thick (experiments 4, 5 and 6).

Unleaded 95 RON gasoline used in experiments 1 to 6 was bought from Total and $1 \%$ of chlorobenzene (AnalaR from BDH Chemicals Ltd (England)) and 1\% of decane (99+\% from Jansen Chimica (Geel, Belgium)) were added as internal standards.

A sample of "Carplan" automotive topcoat thinner (Tetrosyl Ltd, Bury, England) was used for experiment 7.

Air to fill the nylon bags

To simulate other samples in close contact with the simulated fire debris, empty bags were used. As the ignitable liquid analysis requires headspace analysis, the bags were filled with air, as they would have if they were being used to pack fire debris, in order to maintain a consistent bag volume. The air to fill the bags was pumped from a STNC double acting pneumatic cylinder, model TGU125X625 (TRIEN HUNG Trading \& Service Co., Ltd., Vietnam), fitted with an adjustable end-stop. The volume of air was set to fill the bags with no overpressure and bags of the same brand were filled with the same volume of air. CSI Equipment nylon bags were filled with approximately $1750 \mathrm{~mL}$ of compressed air and BVDA nylon bags with approximately $1220 \mathrm{~mL}$.

Two bags of each brand were filled with air for blank analyses and the headspace was extracted and analysed as the samples. Before starting to fill the next bag a blank of the pump air was analysed, except for experiment 7 (oxygenated solvent experiment) as the pump had not been in contact with any material for two months by then. 


\section{Cotton rag}

A piece of white cotton fabric was bought from a local store and washed before use with water, at $60^{\circ} \mathrm{C}$. To simulate a Molotov cocktail wick, pieces approximately the size of an A4 sheet of paper $(210 \mathrm{~mm} \times 297 \mathrm{~mm})$ were cut with scissors previously washed with Decon® 90 laboratory detergent (Decon Laboratories Ltd, England). Each piece of cotton fabric was stored in a CSI Equipment nylon bag. The bags were filled with air using the air pump, and sealed at both ends by the "swan-neck" method using plastic cable ties, as recommended by the former UK Forensic Science Service. The cotton rags were numbered 1 to 6 , as the experiments number. In order to check for any interfering compound from the cotton the headspace of the bags was extracted and analysed using the same instrumental conditions as the samples, on the same day they were closed in the bag. They were analysed again two weeks later, in order to check if there was any variation with time. For the oxygenated solvent experiment (experiment 7) the cotton rag was cut and used in the same day, no blank analysis was done as it had been shown by the other six samples that no interfering compounds were present.

Experimental methodology

Nylon bags were sealed at both ends as recommended by the former UK Forensic Science Service. This advice was given to minimise the risk of leakage or contamination that were occasionally seen due to poor quality heat seals in the closed ends of some batches of bags. The simulated heavy loaded fire debris sample was prepared the following way: a nylon bag was sealed at the closed end with a swan-neck and a plastic cable tie; $10 \mathrm{~mL}$ of the mixture of gasoline containing the internal standards were added to the numbered cotton rag, which was promptly put inside the nylon bag; the bag was then immediately filled with 
air using the air pump and sealed in the same way as the other end. Eight nylon bags of the same brand, which simulated other fire debris samples, numbered 1 to 8 , were filled with air from the pump and sealed as previously. Immediately afterwards the bag with the simulated fire debris was put in a 60 litre capacity plastic crate (Integra nesting stackable crate, Schoeller Allibert, Germany), and surrounded by the other eight inflated bags (Fig. 1). The crates were loosely closed and were only opened when a bag was due to be analysed. The plastic crates were of the type typically used to transport evidence to and from forensic laboratories in the UK and were stored at room temperature to simulate real transportation and storage conditions. This procedure was repeated three times with each brand: experiments 1 to 3 with CSI Equipment nylon bags and experiments 4 to 6 with BBVA nylon bags. To study if cross-contamination of heavy loaded gasoline fire debris would occur both in short-term and long-term storage, the bags with air were analysed at room temperature after 2 h, 4 h, 6 h, 24 h, 4 days, one week, and weekly up to eight weeks.

A later seventh experiment was done using the same methodology, with CSI Equipment nylon bags, a brand of nylon bags commonly used in the UK, and $10 \mathrm{~mL}$ of automotive topcoat thinner added to the cotton rag as a heavy loaded oxygenated solvent fire debris (experiment 7). The bags with air surrounding the sample were analysed daily for seven days.

\section{Sample extraction and GC/MS analysis}

The headspace of the nylon bags inflated with air were extracted with SPME $(65 \mu \mathrm{m}$ film bi-polar PDMS/DVB from SUPELCO, Bellafonte, PA, USA) for 15 min. Contact of the fibre with the bag headspace was done by piercing the bag with the SPME needle and exposure of the fibre. The hole was closed with Sellotape ${ }^{\circledR}$ (Henkel Ltd, England) following common UK fire debris laboratory practice. For each experiment the bags 
surrounding the simulated fire debris were analysed in numerical order 1 to 8 and after bag 8 it re-started from bag 1.

The analyses were performed on a gas chromatograph Trace GC Ultra coupled with a mass spectrometer detector DSQ II (GC/MS) from Thermo-Electron Corporation (Massachusetts, United States). The GC was equipped with a Restek (Bellefonte, USA) Rxi ${ }^{\circledR}-5$ sil MS column $30 \mathrm{~m}$ length, $0.25 \mathrm{~mm}$ internal diameter and $0.25 \mu \mathrm{m}$ film thickness, using helium as carrier gas. The injector was at $250^{\circ} \mathrm{C}$ and the split ratio 1:50 to represent casework; The carrier gas was at constant flow of $1.2 \mathrm{~mL} / \mathrm{min}$; The oven temperature started at $50^{\circ} \mathrm{C}$ for $5 \mathrm{~min}$ and increased at $20^{\circ} \mathrm{C} / \mathrm{min}$ to $280^{\circ} \mathrm{C}$ where it was maintained for $8 \mathrm{~min}$.

The transfer line and the mass spectrometer source were at $250^{\circ} \mathrm{C}$ and the mass range scanned was $30-350$ amu with a scan rate of 1.5 scans/s. The SPME fibre was desorbed in the GC/MS injector for $1 \mathrm{~min}$.

\section{Results}

Background contamination from the air used to fill the nylon bags

The results of the blanks of the two brands of bags filled with air showed the presence of four peaks, the first corresponding to air (identified from now on as 'a1'), and the main peak identified as 2,2,4,6,6-pentamethylhept-3-ene with two small nearby peaks, identified as 2,4,4-trimethylpent-1-ene (group identified from now on as 'a2'). These peaks have not been seen before as background in nylon bags of these two brands used by the authors in the past. The compounds were assumed to be air pump background.

Cross-contamination results for heavy loaded gasoline samples experiments

The identification of gasoline in contamination and cross-contamination studies do not require a full pattern of target compounds. A partial pattern, or the presence of some 
compounds identified in the analysis of the contaminated sample, should be considered cross-contamination as it may produce a false positive result. For this study the results were considered positive for cross-contamination when a compound present in gasoline could be identified in an adjacent bag filled with air.

The cotton rags were analysed before the experiments and no matrix effect was noticed after two days or two weeks. All analyses showed the presence of the same background compounds present in the blank samples, originally from the air used to fill the bags. The retention time of the internal standard decane was the same retention time of 2,2,4,6,6pentamethylhept-3-ene present in the air that filled the bags.

Results of the time for detection of cross-contamination and compounds identified are in table 1. Cross-contamination due to toluene was identified in experiments 1 and 3 (with CSI Equipment nylon bags) after four days, and in experiments 4, 5 and 6 (with BVDA nylon bags) after two weeks. Experiment 2 was not possible to analyse after four days, but toluene was also identified in the subsequent analysis, after one week. Toluene was the first compound detected in all experiments and was present in the majority of the samples afterwards. Results of the analysis after four days and two weeks of experiment are shown in Fig. 2 and 3.

The compounds detected in cross-contamination were the same in both brands of bags. The three experiments with the CSI Equipment nylon bags showed cross-contamination of toluene and the full $\mathrm{C}_{2}$-alkylbenzenes group ethylbenzene, $m$-/ $/ p$-xylene and $o$-xylene after three weeks, and their presence remained identified until the eighth week. On the other hand, the three experiments with the BVDA nylon bags showed more intra-variation, as although $m-/ p$-xylene were identified in two experiments along with toluene, the full $\mathrm{C}_{2-}$ alkylbenzene group was only identified one time in each one, after four, six and seven 
weeks. In Fig. 4 is shown the results of the six experiments at the time corresponding to the identification of the maximum abundance of toluene and the $\mathrm{C}_{2}$-alkylbenzenes.

Comparison of the results after eight weeks (Fig. 5) show the decrease in the abundance of the compounds identified in cross-contamination. Toluene is only identified in one experiment of BVDA nylon bags while the $\mathrm{C}_{2}$-alkylbenzene group is identified in two experiments of the CSI nylon bags.

All the bags containing the rag with gasoline became soft after some days. This was noticed between the fourth day and one week of experiment in all bags.

During the experiment some bags lost volume. It may be related with the sealing or with the puncture done for the SPME extraction, which was closed with Sellotape ${ }^{\circledR}$ afterwards.

Cross-contamination results for the heavy loaded automotive paint thinner sample experiment

Results were positive for cross-contamination after two days, when 2-propanone was identified. On the third day, 2-butanone and toluene could also be identified. No further compounds were identified until the seventh and last day of the experiment (Fig. 6).

\section{Discussion}

\section{Cross-contamination results for the gasoline sample experiments}

Cross-contamination did occur with both BVDA and CSI Equipment brands of nylon bags. Time for cross-contamination detection was four days for CSI Equipment nylon bags and two weeks for BVDA bags. The compounds identified in both brands were the same, the first one was toluene and afterwards the aromatic $\mathrm{C}_{2}$-alkylbenzenes group, at three weeks for CSI Equipment bags and four, six and seven weeks for BVDA bags. The 
similarity between brands in terms of compounds detected was expected as the bags are made of the same material (nylon 11 a.k.a. polyamide-11). The original cause is the nylon material itself, the low permeability of the nylon to hydrocarbons (10) and its low rate diffusion of nonpolar compounds (9), which is the reason that led some authors to state that nylon bags do leak after some time $(2-8,14)$ and that cross-contamination occurs. The difference in time to detect cross-contamination and the differences in time to identify the $\mathrm{C}_{2}$-alkylbenzes group in the two brands of nylon bags was unexpected and much higher than it would be expected from bags of the same material in the same conditions. It was considered the difference in the dimensions of the bags of each brand and the different inner air volume (460mm x 600mm for CSI Equipment bags with $1750 \mathrm{~mL}$ of air volume and 250mm x 500mm for BVDA bags with $1220 \mathrm{~mL}$ of air volume), which implied different contact areas between the bags $\left(0.552 \mathrm{~m}^{2}\right.$ for CSI bags and $0.250 \mathrm{~m}^{2}$ for BVDA bags not taking into account the swan necking), and would have influenced the crossing of the compounds through the nylon membrane. These differences were not thought to fully explain the differences, but reinforce the conclusion reached by previous authors that some brands of nylon bags may not be appropriate as container for ignitable liquids.

The abundance of compounds detected due to cross-contamination generally firstly increased and then decreased with time. In experiments 1 and 2 after eight weeks, and in experiment 3 after seven weeks (CSI Equipment bags), a poorly defined peak was seen at the retention time of toluene, although with a the mass spectrum too poor to give an acceptable match with any compound. This decrease and intra-experiment variations led to negative results for cross-contamination of experiment 4 and 6 (BVDA bags) respectively in week 7 and 6, and positive results in the week after. The variation in the time frame for detection of the aromatic group amongst the BVDA bags is also significant. Within each 
brand, the variation in time for the compounds to be detected and their amount may be due to the non-rigid geometry of the bags, which implied that the contact area of the bags with air and the sample bag with gasoline varied, influencing the crossing of compounds through the nylon membrane. Within the crate and within the bags an equilibrium between the concentration of compounds would tend to be established. However, the crate is not a closed system and was opened every time a sample was analysed, therefore the gasoline that leaked from the sample bag was being released to the environment. A smell of gasoline was noticed in the crates during the first four-six weeks clearly indicating some leakage, decreased with time and no odour was noticed in the last two weeks of the experiments.

\section{Comparison of the results with previous studies}

The reason for different results from several studies may probably be attributed to variation factors such as the type of nylon, the brand, and thickness of the bags, the amount of ignitable liquid used and whether it was in contact with the nylon membrane, volume of the bags, spatial distribution of the bags in contact and container for the bags, method of extraction and analytical technique. All the studies used GC with flame ionisation detection for analysing the samples, although only more recent studies used mass spectrometer detectors.

The compounds identified in cross-contamination were the same identified as leaking from nylon bags in the Forensic Science Service (FSS, UK) studies $(5,6)$, although those studies did not detect cross-contamination bag-to-bag. One study used an unknown brand of nylon bags, $2 \mathrm{~mL}$ and $5 \mathrm{~mL}$ of gasoline with no direct contact with the nylon bag, in normal casework conditions over a period of eight weeks time (6). The other study used Vynapac Ltd. nylon bags $0.04 \mathrm{~mm}$ thick, capacity of about one litre, and $25 \mu \mathrm{L}$ of gasoline. Leaking was found after $24 \mathrm{~h}$ at ambient temperatures but it was concluded that no significant cross- 
contamination through casework nylon bags occurs, which was explained by the very slow rate of diffusion of volatile hydrocarbons through the bags (5).

The results of this study are contrasting with the results obtained with nylon bags from Grand River®, used in America. Stryjnik and Hong-You (4) used this brand of nylon bags containing paper towels spiked with different classes of ignitable liquid as a solvent mixture, gasoline, kerosene and light, medium and heavy gasoline distillates, sealed with swan-neck and closed in a box. No cross-contamination in an adjacent nylon bag was detected after approximately five months. However, in that study $1 \mathrm{~mL}$ of the ignitable liquid mixture was used, while in this study $10 \mathrm{~mL}$ were used. Mann used the same brand of bags and studied the loss during room temperature storage using $10 \mu \mathrm{L}, 100 \mu \mathrm{L}$ and $1 \mathrm{~mL}$ of a 1:1 mix of gasoline and diesel fuel oil and concluded that cross-contamination was not an issue because minute leakage was found (8). On the other hand, Henry did find crosscontamination at very low levels, analysed after 1 and 2 weeks, using as sample a Kimwipe ${ }^{\circledR}$ soaked in 1:1 mixture of gasoline and diesel (7).

Carlsson et al. (2) concluded that nylon bags sealed with cable ties retain cyclic and aliphatic hydrocarbons, but using 'quite a lot' of gasoline and 'technical alcohol' (92\% w/w ethanol, $2 \% \mathrm{w} / \mathrm{w}$ acetone, and 5\% w/w 2-butanone) cross-contamination occurs within five days. The brand of the bags and the volume of the gasoline are unknown, and the compounds found in other bags where cross-contamination occurred were not identified, but the time results for cross-contamination detection are comparable with the results for the CSI Equipment nylon bags. It would be expected that the polar compounds would cross the nylon membrane, given previous research $(1,2)$.

The aromatic compounds found in cross-contamination are the same as Hendrikse and Grutters $(3,14)$ found after 57 days of experiment. Their study concluded that nylon-11 bags obtained from De Ridder B.V. (Uitgeest, the Netherlands), $15 \mathrm{~cm}$ x $15 \mathrm{~cm}$, containing filter 
paper spiked with $10 \mu \mathrm{L}$ of gasoline, $100 \mathrm{~mL}$ of air and heat-sealed, started leaking within seven days. In the same conditions, cross-contamination occurred for toluene after 8 days and for ethylbenzene and $m$ - $/ p$-xylene after 29 days. Interestingly, $o$-xylene was not identified, while in this study the $\mathrm{C}_{2}$-alkylbenzenes showed similar behaviour.

\section{Cross-contamination results for automotive topcoat thinner experiment}

Results indicated the occurrence of cross-contamination for toluene and the ketones 2propanone and 2-butanone. Ketones are polar compounds, and it was expected that this type of compounds would leak and then eventually be present in other bags, as it is known that polar compounds are not efficiently retained by nylon bags $(1,2)$. The time frame for detection of the aromatic compound toluene, three days, was similar to the experiments with gasoline, where samples were analysed on the first and fourth day, therefore no information is available on the third day that may be compared. Cross-contamination of the $\mathrm{C}_{2}{ }^{-}$ alkylbenzenes group was not found, which was unexpected. This may be due to differences in the relative concentrations of $\mathrm{C}_{2}$-alkylbenzenes in gasoline and the oxygenated solvent though no quantification was carried out in this study.

\section{Possible consequences of cross-contamination in fire debris analysis}

The identification of the aromatics toluene and/or the $\mathrm{C}_{2}$-alkykbenzenes group (ethylbenzene, $m$-/ $p$-xylene and $o$-xylene) in a fire debris sample due to cross-contamination may lead to a false positive result or a wrong result. The ASTM ignitable liquid classification class of the light aromatic products (range $\left.\mathrm{C}_{4}-\mathrm{C}_{9}\right)(28)$ include xylenes and toluene as solvents and may comprise ethylbenzene and $\mathrm{C}_{2}$-alkylbenzenes, as in the rubber and chemical manufacturing industries. Also, they can be used as base for other products (may also contain ethylbenzene) such as some paint and varnish removers, automotive parts 
cleaners $(1,15)$ adhesives, inks, resins, cleaning agents, leather tanners, and pesticide carrier solvents. Many of these products also contain other aromatics and may also contain alkanes, cycloalkanes, alcohols, acetones, or aldehydes. Other classes of compounds may contain toluene and the $\mathrm{C}_{2}$-alkylbenzenes, aromatics are always present in traditional medium and heavy distillates and may be present in light distillates (15). For example, they can be found in lacquer thinner, an oxygenated solvent (16).

\section{Possible consequences of cross-contamination results for transport and storage of fire} debris evidence

The risk of cross-contamination should be taken into account by fire investigators and laboratory personnel. Sometimes fire debris collected from a scene does smell strongly of ignitable liquids. In those cases the fire investigator should give special attention to the transport and storage of fire debris samples, by separating the strongly smelling samples from other evidence using different bags/boxes/crates. The laboratory should be warned about the presence of this type of sample in order to store it away from other evidence.

\section{Toluene and EU legislation}

It should be noted that the proportion of toluene in solvents has substantially decreased since 2005, when European Directive 2005/59/EC came into force (17). Toluene is now classified as carcinogenic according to European Council Directive 67/548/EEC of 1967. As a result it is banned in concentrations exceeding $0.1 \%$ in consumer products.

As a consequence of this Directive the formulations of solvent lacquers, thinners and adhesives may now contain a higher proportion of oxygenated compounds. These formulations may pose an even greater risk of penetration through nylon bags. This potential problem requires further research. 


\section{Conclusions}

This research showed that cross-contamination of the BVDA and CSI Equipment nylon bags with heavy loaded gasoline samples and with automotive topcoat thinner, in conditions similar to the ones used in the UK by fire investigators in the field, does occur. These findings are important with respect to the integrity of evidence samples.

The two brands of nylon bags used for the experiments with gasoline performed significantly differently in the period of time to detection of cross-contamination. BVDA nylon bags cross-contamination was found after two weeks, whereas using CSI Equipment nylon bags it was found after only four days. The compounds identified in both brands of bags were the aromatic hydrocarbons toluene, ethylbenzene, $m$ - $/ p$-xylene, and $o$-xylene.

In the case of a sample heavily loaded with automotive topcoat thinner, using CSI Equipment nylon bags, a brand commonly used in the UK, cross-contamination was detected after two days, when 2-propanone were identified. 2-butanone and toluene were identified on the third day.

In conclusion, there is consensus amongst the forensic community that nylon bags do leak, and different cross-contamination results are probably dependent on the experiment conditions.

The finding of cross-contamination may have impact in the forensic science community and suggestions on transport and storage of fire debris may be concluded from this research: The fire investigator or CSI needs to be aware that nylon bags containing heavy loaded samples should be transported and stored away from other fire debris samples; Nylon bags should be kept with enough space around them so they are not compressed, which may make them lose the internal headspace volume and consequently lose any possible ignitable liquid present in the debris; The laboratory personnel, although usually more aware of the 
packaging characteristics and storage of samples, needs to be informed on the presence of heavily loaded flammable liquid fire debris.

Double bagging is a common practice in some laboratories and should be considered when collecting heavy loaded ignitable liquids samples.

\section{Acknowledgments}

To Tamar Garcia-Sorribes for her help in the laboratory; to Carlos Gregório for his contribution to the final artwork.

\section{References}

1. Stauffer E, Dolan JA, Newman R. Fire Debris Analysis. Amsterdam, The Netherlands: Elsevier Academic Press, 2008.

2. Carlsson G, Kopp S, Wistedt I. Conserving samples of fire debris suspected of containing accelerants. Advances in Forensic Sciences 1995;1:187-90.

3. Hendrikse J. Performance Testing and Comparison of Different Fire Debris Bags. In: Proceedings of the American Academy of Forensic Sciences; 2011 Feb 21-26; Chicago (IL). Colorado Springs (CO):American Academy of Forensic Sciences, 2011;101.

4. Stryjnik AE, Hong-You R. Evaluation of the Effectiveness of Nylon Bags as Packaging for Fire Debris. In: American Academy of Forensic Sciences, editor. Proceedings of the American Academy of Forensic Sciences; 2004 Feb; Dallas (TX). Colorado Springs (CO):American Academy of Forensic Sciences, 2004;86.

5. Bates JW, Allison T. Diffusion of hydrocarbon vapours from fire accelerants through nylon bags. Wetherby: Forensic Science Laboratory, Home Office Forensic Science Service; 1987 May. Technical Note No.: 571. 
6. Kelly L. Investigation into the validity of using nylon bags for the packaging of exhibits containing fire accelerants. Chorley: Forensic Science Laboratory, Home Office Forensic Science Service; 1986 March-September.

7. Henry CL. Study of nylon bags for packaging fire debris. CAC News $2008,4^{\text {th }}$ Quarter:30-32.

8. Mann DC. In search of the perfect container for fire debris evidence. Fire \& Arson Investig 2000 Apr;50(3):21-5.

9. http://www.bvda.com/EN/sect13/en_13_1a.html

10. http://www.csiequipment.com/nylon-fire-bags---18x24_p31661.aspx

11. http://wales.gov.uk/topics/statistics/headlines/fire2012/120228/?lang=en

12. International Association of Fire Chiefs, International Association of Arson Investigators, National Fire Protection Association. Fire Investigator: Principles and Practice to NFPA921 and 1033. 3rd ed. Sundbury, MA: Jones \& Bartlett Learning, 2012.

13. Yoshida H, Kaneko T, Suzuki S. A solid-phase microextraction method for the detection of ignitable liquids in fire debris. J Forensic Sci 2008;53(3):668-76.

14. Grutters MMP, Dogger J, Hendrikse JN. Performance testing of the new AMPAC fire debris bag against three other commercial fire debris bags. J Forensic Sci 2012;57(5):1290-98.

15. ASTM-American Standards and Testing Materials. Standard Test Method for Ignitable Liquid Residues in Extracts from Fire Debris Samples by Gas Chromatography-Mass Spectrometry - E1618-11. ASTM International 2011.

16. Newman R, Gilbert M, Lothridge K. GC-MS guide to ignitable liquids. Boca Raton, FL: CRC Press LLC, 1998. 
1

2

3

4

5

6

7

8

9

10

11

12

13

14

15

16

17

18

19

20

21

22

23

24

25

26

27

28

29

30

31

32

33

34

35

36

37

38

39

40

41

42

43

44

45

46

47

48

49

50

51

52

53

54

55

56

57

58

59

60

17. Directive 2005/59/EC of the European Parliament and of the Council of 26 October 2005. Official Journal of the European Union $200525^{\text {th }}$ Nov;L309.

Additional information and reprint requests:

Filipa Belchior, M.Sc.

Polícia Judiciária

Rua Gomes Freire

1169-007 Lisbon

Portugal

E-mail: filipa.belchior@pj.pt / fbelchior@yahoo.com 


\section{Table 1}

Time for detection of cross-contamination of heavy loaded gasoline fire debris and compounds identified.

\begin{tabular}{|c|c|c|c|c|c|}
\hline $\begin{array}{l}\text { Sample } \\
\text { number }\end{array}$ & $\begin{array}{l}\text { Brand of } \\
\text { nylon bag }\end{array}$ & $\begin{array}{l}\text { First compound } \\
\text { detected }\end{array}$ & $\begin{array}{c}\text { Time for } \\
\text { cross- } \\
\text { contamination } \\
\text { detection }\end{array}$ & $\begin{array}{l}\text { Compounds } \\
\text { identified in } \\
\text { cross- } \\
\text { contamination }\end{array}$ & $\begin{array}{c}\text { Time for } \\
\text { identification of } \\
\mathrm{C}_{2} \text {-alkylbenzene } \\
\text { group }\end{array}$ \\
\hline 1 & \multirow{3}{*}{$\begin{array}{c}\text { CSI } \\
\text { Equipment }\end{array}$} & \multirow{6}{*}{ Toluene } & 4 days & \multirow{6}{*}{$\begin{array}{c}\mathrm{C}_{2} \text {-alkylbenzene } \\
\text { group: } \\
\text { ethylbenzene } \\
m \text {-/p-xylene } \\
o \text {-xylene }\end{array}$} & 3 weeks \\
\hline 2 & & & 1 week $^{1}$ & & 3 weeks \\
\hline 3 & & & 4 days & & 3 weeks \\
\hline 4 & \multirow{3}{*}{ BVDA } & & 2 weeks & & 6 weeks \\
\hline 5 & & & 2 weeks & & 7 weeks \\
\hline 6 & & & 2 weeks & & 4 weeks \\
\hline
\end{tabular}

${ }^{\mathrm{T}}$ Experiment 2 was not analysed after 4 days. 
FIG. 1 - Schematic representation of the experimental setup for cross-contamination tests - sample bag in the centre and showing six of the eight bags with air in close contact (bag design adapted from the former UK Forensic Science Service packaging advice note of arson related evidence). $152 \times 96 \mathrm{~mm}(300 \times 300 \mathrm{DPI})$ 


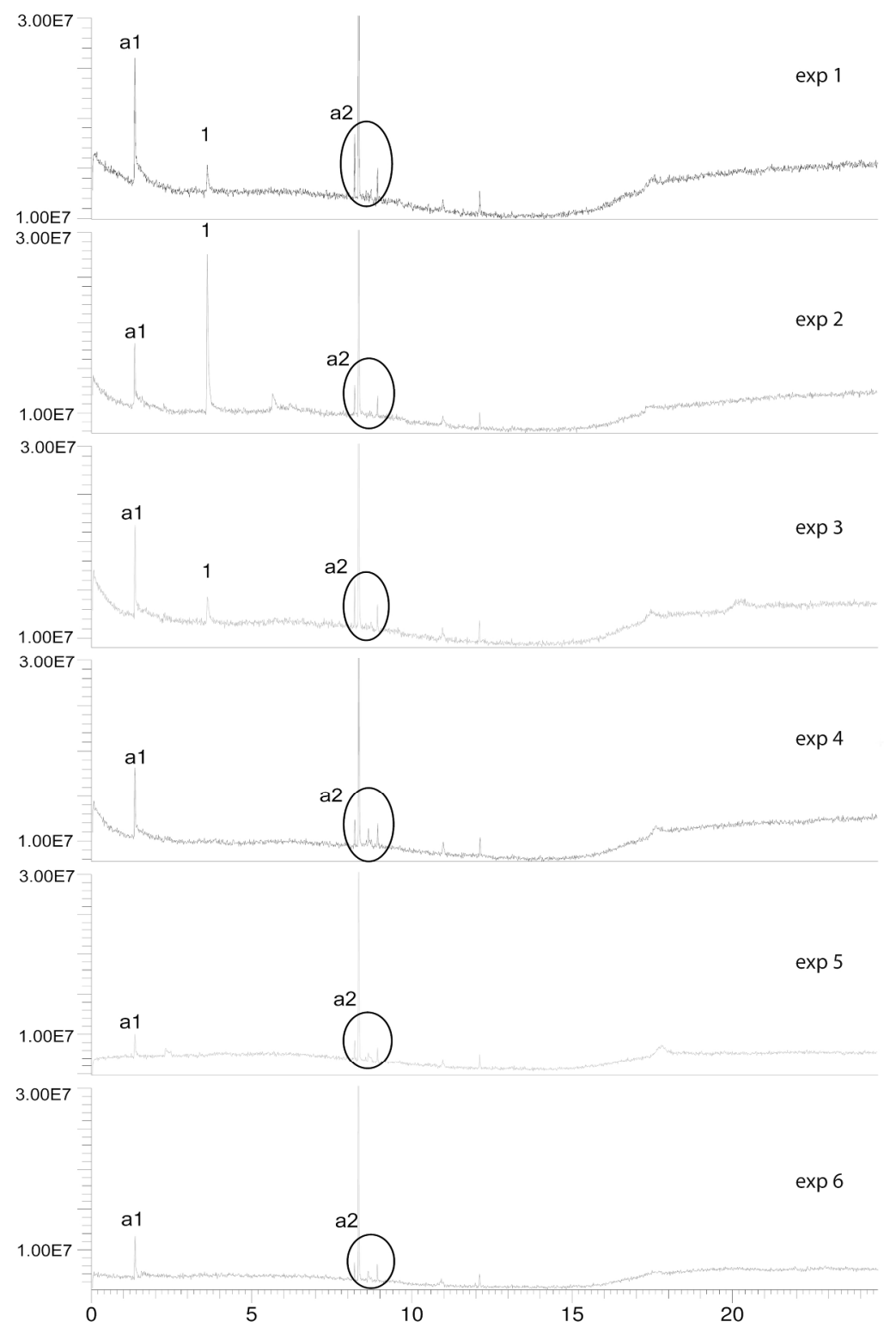

FIG. 2 - TIC of experiments 1, 3, 4, 5 and 6 after four days; and experiment 2 after one week. 1: Toluene; a1 and a2: air pump compounds. $199 \times 285 \mathrm{~mm}(300 \times 300 \mathrm{DPI})$ 


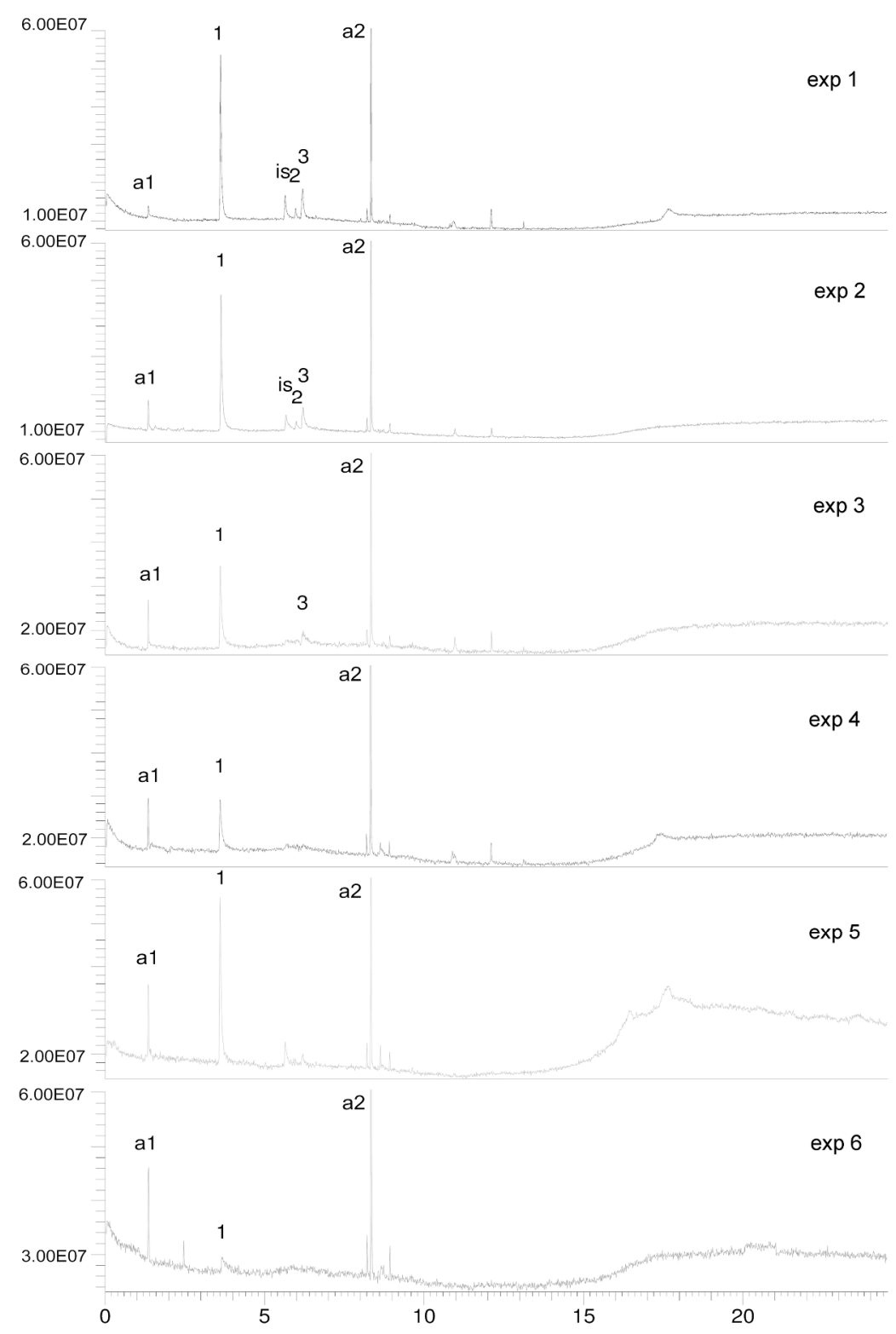

FIG. 3 - TIC of experiments 1 to 6 after two weeks. 1: Toluene; is: internal standard chlorobenzene; 2: ethylbenzene; $3: \mathrm{m}-/ \mathrm{p}-x y l e n e ; ~ a 1$ and a2: air pump compounds. $199 \times 285 \mathrm{~mm}(300 \times 300$ DPI $)$ 


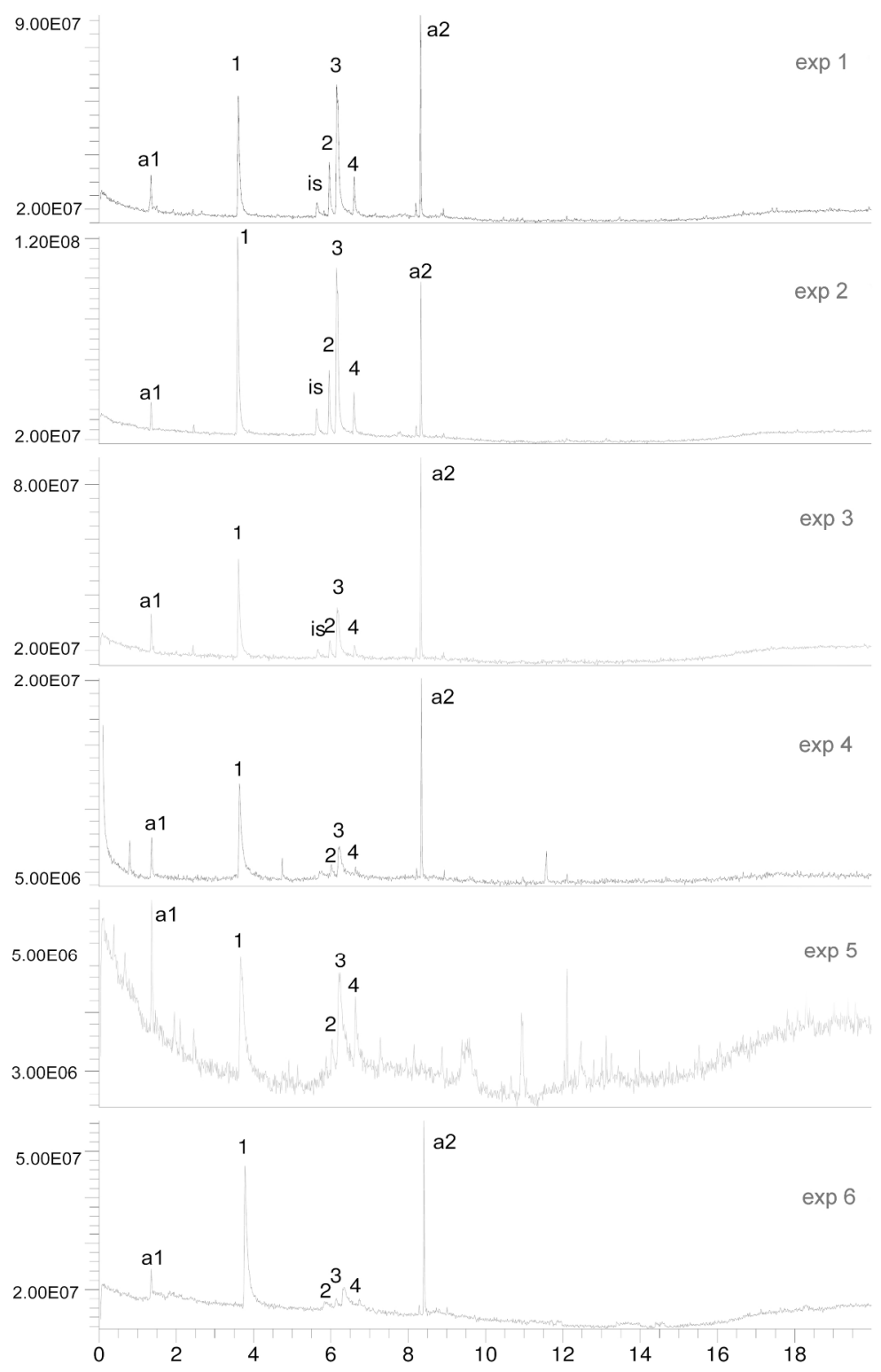

FIG. 4 - TIC of experiments 1 to 6 at the time for identification of the maximum abundance of Toluene and the C2-alkylbenzene group. 1: Toluene; is: internal standard chlorobenzene; 2 : ethylbenzene; $3: \mathrm{m}-/ \mathrm{p}$ xylene; 4: o-xylene; 1 and a2: air pump compounds.

$199 \times 285 \mathrm{~mm}(300 \times 300$ DPI $)$ 


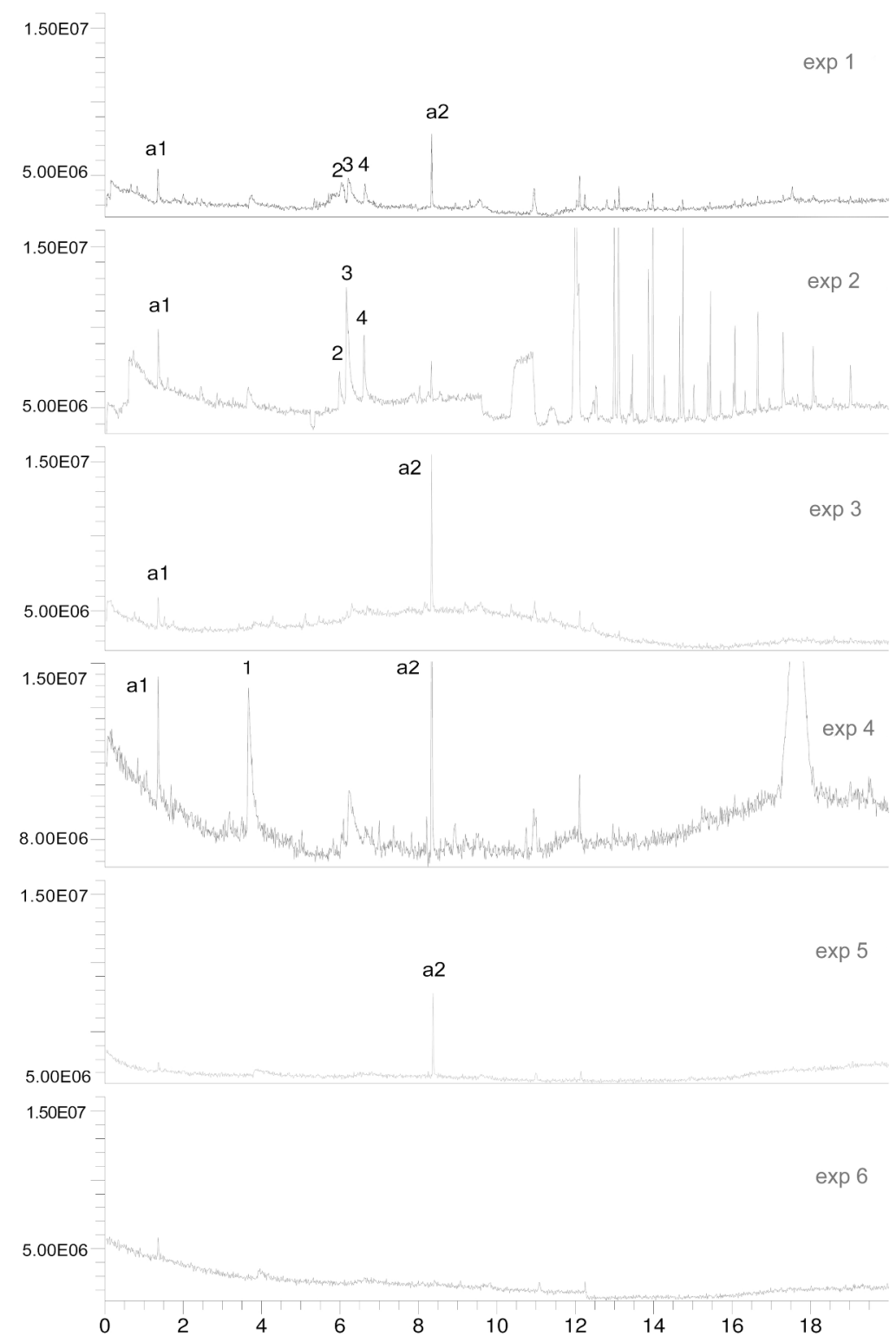

FIG. 5 - TIC of experiments 1 to 6 after eight weeks of experiment. 1: Toluene; 2: ethylbenzene; 3: m-/pxylene. a1 and a2: air pump compounds. The other peaks are system/column peaks. $199 \times 285 \mathrm{~mm}(300 \times 300 \mathrm{DPI})$ 


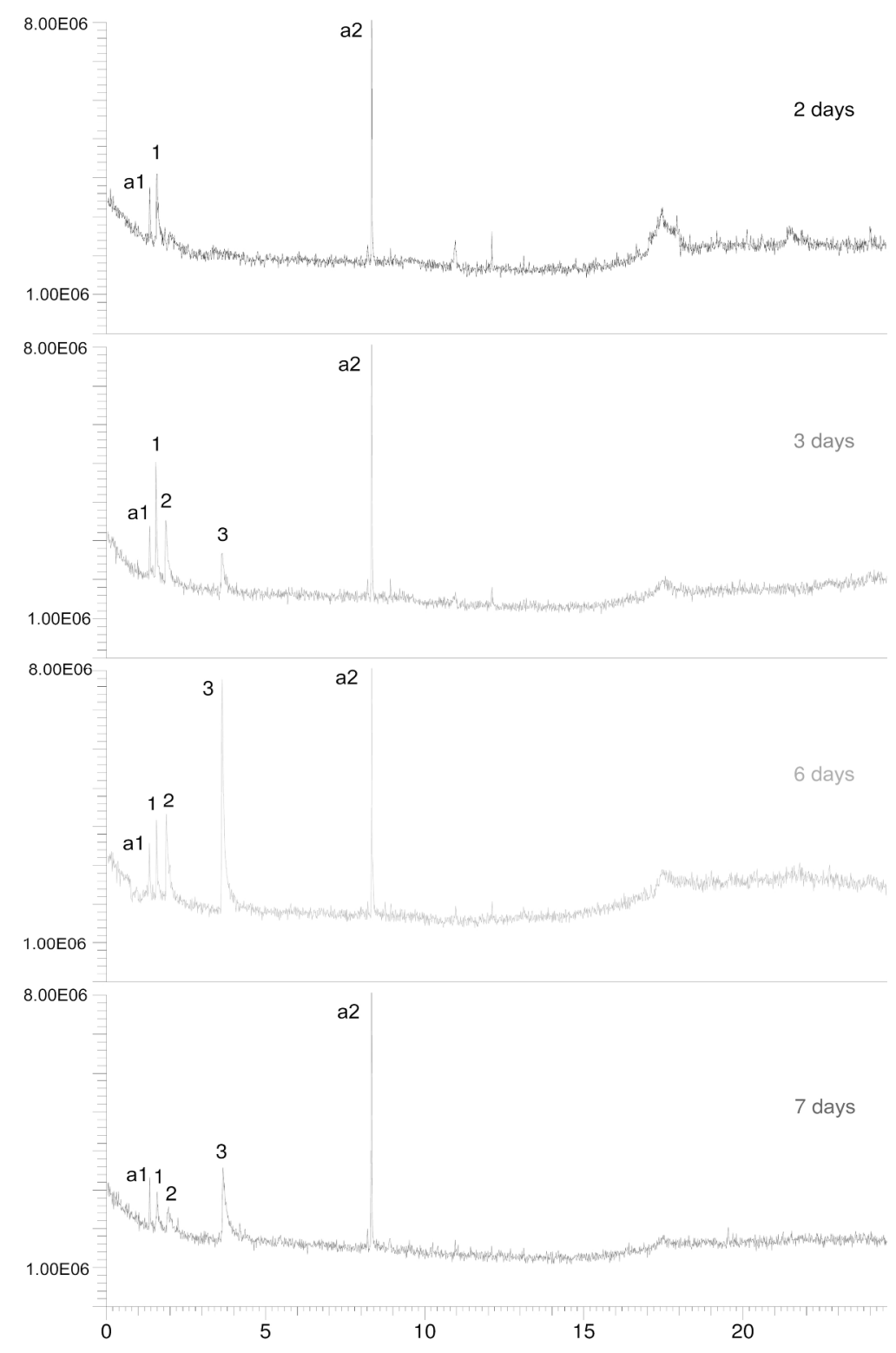

FIG. 6 - TIC of experiment 7. 1: 2-propanone; 2: 2-butanone; 3: toluene. a1 and a2: air pump compounds. The other peaks are system/column peaks. $199 \times 285 \mathrm{~mm}(300 \times 300 \mathrm{DPI})$ 